\title{
The role of location in evaluating racial wage disparity
}

\author{
Dan A Black ${ }^{1}$, Natalia Kolesnikova ${ }^{2 *}$, Seth G Sanders ${ }^{3}$ and Lowell J Taylor ${ }^{4}$
}

\author{
${ }^{*}$ Correspondence: \\ natalia@olemiss.edu \\ ${ }^{2}$ University of Mississippi, University, \\ USA \\ Full list of author information is \\ available at the end of the article
}

\begin{abstract}
A standard object of empirical analysis in labor economics is a modified Mincer wage function in which an individual's log wage is a function of education, experience, and race. We analyze this approach in a context where individuals live and work in different locations (thus facing different housing prices and wages). Our model justifies the traditional approach, but with the important caveat that the regression should include location-specific fixed effects. Empirical analysis of men in U.S. labor markets demonstrates that failure to condition on location causes us to significantly overstate the decline in black-white wage disparity over the past 60 years.
\end{abstract}

JEL codes: J31, J71, R23

Keywords: Wage regressions, Racial wage disparity, Theory of local labor markets

\section{Introduction}

In hundreds of studies social scientists have examined the role of minority status in wage determination by estimating variants of the Mincer earnings function ${ }^{1}$,

$$
\ln \left(w_{i}\right)=\beta_{0}+\beta_{1} R_{i}+\beta_{2} E_{i}+\gamma\left(X_{i}\right)+\epsilon_{i} ;
$$

the expected log wage of individual $i$ is specified to be a function of an indicator variable for minority demographic status $R_{i}$ (e.g., race, ethnicity, or immigrant status), education $E_{i}$ (or an alternative measure of human capital), and also, typically, some function of such covariates as age or experience, given by $\gamma\left(X_{i}\right)$. An estimated negative value of $\beta_{1}$ is taken as an indication of wage disparity that adversely affects minority workers.

For example, a very large literature uses regression analyses along the lines of equation (1) to document racial disparities among blacks and whites in the U.S. The disadvantaged position of black workers is understood to be the consequence of discrimination in labor markets and racial differences in the pre-market development of human capital ${ }^{2}$.

Here we study the properties of wage gap estimates from regression (1) when individuals live in locations that have differing prices, especially differing wages and housing prices. The central point of our paper is that if we intend to interpret an estimated wage gap as a welfare difference between groups, we need to account for the fact that these groups may face different local prices, e.g., may on average live in cities with differing housing prices.

To structure our thinking about this problem we use a theoretical framework, along the lines Haurin (1980) and Roback (1982), in which equilibrium prices and wages

(c) 2013 Black et al.; licensee Springer. This is an Open Access article distributed under the terms of the Creative Commons

Attribution License (http://creativecommons.org/licenses/by/2.0), which permits unrestricted use, distribution, and reproduction in any medium, provided the original work is properly cited. 
vary across cities because of differences in location-specific amenities and/or productivity. As is common in such models, we focus on the equilibrium that results when there is costless migration between locations. The distinctive feature of our model is that people belong to two racial groups, one of which suffers disadvantage due to discrimination or due to unmeasured differences in human capital. Given this standard approach to local labor markets, theoretical reasoning leads us to conclude that if preferences are homothetic $-\mathrm{a}$ common, though somewhat restrictive, assumption $-\beta_{1}$ is a meaningful parameter measuring disadvantage for the minority group. But, importantly, consistent estimation of $\beta_{1}$ in general requires the inclusion of location fixed effects into equation (1).

With this observation in mind, we conduct an analysis of black-white wage gaps for men in the United States from 1940 through 2000-work that roughly parallels (and extends) the seminal work of Smith and Welch (1989). We find that an analysis that omits location substantially overstates black-white wage convergence over this period.

Our paper proceeds in four additional sections: Section 2 sets out a standard model of urban differences in prices, and in that context demonstrates that the race wage gapwhether generated by discrimination or by human capital differences-is a constant across different local labor markets if and only if preferences are homothetic. Under that assumption, estimation of a Mincer wage regression typically requires inclusion of location fixed effects. Section 3 presents evidence of the importance of this idea for standard empirical exercises that examine racial wage gaps. Section 4 revisits our theory, asking about the implications of our model if the key assumption of homotheticity is violated. Section 5 provides concluding remarks.

\section{Race wage gaps in a multiple-location model}

Workers supply labor in local labor markets, and across those markets there are often substantial differences in wages and other local prices ${ }^{3}$. Theoretical reasoning in the urban/regional economic literature, in the pioneering work of Haurin (1980) and Roback (1982) and in many papers that followed, suggests that observed location-specific price differences can generally be understood to be the consequences of differences in locations' amenities and location-specific differences in productivity. Our goal is to determine what these models have to say about racial wage disparities in local labor markets.

We begin with a population in which individuals belong to one of two racial groups: a minority group, indicated by $R=1$, and a majority group, indicated by $R=0$. These people live in one of $n$ cities, and consume two goods: a non-housing good that has a price 1 in every location, and housing, which has a price that varies across cities. We designate the rental price of housing $p_{j}$ per unit $(j=1, \ldots n)$. Wages also differ across location, and we want to allow for the possibility of race-based differences in wages: individuals from racial group $R=0$ earn wage $w_{j}^{0}$ in city $j$, while those from group 1 earn $w_{j}^{1}$.

For simplicity, we assume that all workers supply one unit of labor, regardless of where they work. We assume also that all individuals have the same preferences. Finally, as is typical in these models, we assume that there is costless migration between locations. Let the expenditure function for workers of each group ( $R=0$ or 1$)$ living in city $j$ be $e_{j}^{R}=e\left(p_{j}, u_{j}^{R}\right)$. The key equilibrium condition is that workers of both groups must be indifferent over their city of residence; for individuals in each racial group, utility $u_{j}^{R}$ is 
the same in each city. Therefore we can drop the subscript $j$ on utility, and note that equilibrium entails

$$
e\left(p_{j}, u^{0}\right)=w_{j}^{0} \text { and } e\left(p_{j}, u^{1}\right)=w_{j}^{1} \text { for } j=1, \ldots, n .
$$

While $u^{0}$ and $u^{1}$ must each be invariant across cities, utility might differ between demographic groups if their earnings differ. As we have noted, this latter outcome is possible if the two groups differ in terms of productivity or if there is racial discrimination that results in wage disparity. With this in mind, we consider an "equality index" in location $j$, which we define to be the ratio of the wage for the minority group 1 relative to the wage of the majority group 0 ,

$$
I_{j}=\frac{w_{j}^{1}}{w_{j}^{0}}=\frac{e\left(p_{j}, u^{1}\right)}{e\left(p_{j}, u^{0}\right)} .
$$

This equality index will be less than one if the minority group is disadvantaged or greater than one if the minority group is advantaged. Importantly, in general this ratio is seen to depend on the housing price $p_{j}$.

When is the equality index independent of location-specific price variation? First, note that if preferences are such that individuals' expenditure functions takes a "separable" form $e(p, u)=\psi(p) f(u)$, the equality index in location $j$ is $I_{j}=\frac{\psi\left(p_{j}\right) f\left(u^{1}\right)}{\psi\left(p_{j}\right) f\left(u^{0}\right)}=\frac{f\left(u^{1}\right)}{f\left(u^{0}\right)}$, which does not depend on local prices. Second, and more importantly, note that the converse is true. The proof is simple: Let $I_{j}=g\left(u^{0}, u^{1}\right)$, so that the index in location $j$ does not depend on that location's prices. Without loss of generality we can take $u^{0}=1, u^{1}=u$. Then $I_{j}=\frac{e\left(p_{j}, u\right)}{e\left(p_{j}, 1\right)}=g(u, 1)$, so we can write $e\left(p_{j}, u\right)=e\left(p_{j}, 1\right) \cdot g(u, 1)$. Setting $\psi(p) \equiv e(p, 1)$ and $f(u) \equiv g(u, 1)$ we find that the expenditure function has the form $e(p, u)=\psi(p) f(u)$.

A familiar result from price theory is that the expenditure function takes the form $e(p, u)=f(u) \psi(p)$ if and only if preferences are homothetic. We thus have a key proposition: In an equilibrium model of local labor markets, the racial equality index is the same across locations if and only if preferences are homothetic.

As long as preferences are homothetic, it proves quite easy to relate our theory back to the familiar Mincer wage regression (1). Under homotheticity, the form of the expenditure function is $w=\psi(p) f(u)$. Using the logarithmic form of this equation, for a person $i$ living in city $j$ we have

$$
\ln \left(w_{i j}\right)=\ln \left(\psi\left(p_{j}\right)\right)+\ln \left(f\left(u^{R_{i}}\right)\right),
$$

where $R_{i}$ indicates the individual $i$ 's race $\left(R_{i}=0\right.$ or 1$)$. Since $\psi\left(p_{j}\right)$ is independent of utility, local wage levels vary with local prices, but log racial wage disparity is a constant that is invariant with regard to location. Thus we can let $\beta_{0}^{j} \equiv \ln \left(\psi\left(p_{j}\right)\right)+\ln \left(f\left(u^{R_{0}}\right)\right)$ and $\beta_{1} \equiv \ln \left(f\left(u^{R_{1}}\right)\right)-\ln \left(f\left(u^{R_{0}}\right)\right)$, and we have the structural relationship

$$
\ln \left(w_{i j}\right)=\beta_{0}^{j}+\beta_{1} R_{i},
$$

where $\beta_{1}$ the penalty (or premium) to minority status.

Mincer famously provided theoretical reasoning to expect that log wage increases linearly in years of education $\left(E_{i}\right)$, and in addition is increasing in experience. If so, and if the returns to education and experience are the same for minority and majority workers, $f(u)$ should be proportional to $e^{\beta_{2} E_{i}+\gamma\left(X_{i}\right)}$, where $\gamma\left(X_{i}\right)$ is an increasing function of experience 
$\left(X_{i}\right)^{4}$. Then, assuming additional variation in the observed log age can be represented by an independent additive error term $\epsilon_{i j}$, we have

$$
\ln \left(w_{i j}\right)=\beta_{0}^{j}+\beta_{1} R_{i}+\beta_{2} E_{i}+\gamma\left(X_{i}\right)+\epsilon_{i j} .
$$

This is the same as the familiar equation (1) with the important proviso that local labor market fixed effects $(j=1, \cdots, n)$ must be included ${ }^{5}$. More generally, it might be advisable to treat the return to education as non-linear (see, e.g., Heckman et al. 2006), which is the approach we take in our empirical application below.

In the U.S. there is large variability in housing prices across cities. In general, utility losses individuals experience by locating in a particularly expensive city will differ among individuals. Furthermore, these utility losses might systematically be correlated with race, if only because blacks are on average poorer than whites. This is where the homotheticity assumption comes into play. When an individual experiences a price increase, real income of course decreases. But if preferences are homothetic, the proportional decrease in real income is the same for all individuals ${ }^{6}$. Put another way, the proportional increase in the wage needed to induce people to live in a particularly expensive city will be the same across all individuals, and therefore the proportional wage gap between whites and blacks will be the same in each location. All that is required to estimate this gap is that the researchers estimate the wage regression using the $\log$ of wage as the dependent variable (i.e., use the Mincer specification) and include fixed effects to capture location-specific price differentials.

On the other hand, if there are serious violations of homotheticity, equilibrium blackwhite wage gaps will differ across cities. The same is true if markets are substantially out of equilibrium. We return to these issues in Section 4 below. First, though, we turn to empirical implementations of our key regression (6), asking if the inclusion of location fixed effects matters for inferences about racial wage gaps in the U.S.

\section{The importance of location for evaluating the black-white wage gap}

We consider here an important application-measuring the black-white wage convergence over the past few decades. A generation of labor economists is now familiar with the basic picture presented in Smith and Welch's seminal 1989 paper, "Black Economic Progress After Myrdal." Smith and Welch demonstrated that for men the black-white gap in weekly wages declined from -57 percent in 1940 to -27 percent in 1980 . Here we update the basic facts about this trend by evaluating also results in 1990 and 2000, and we proceed with an additional contribution: we evaluate the role of location in drawing inferences about the trend in black-white wage gap.

Like Smith and Welch (1989), and many other authors, we estimate black-white wage gap using public use samples from the U.S. Decennial Census. There are substantial advantages to these data for this purpose. First, they provide us with an opportunity to examine the economic progress of African Americans relative to whites over a long period using data from instruments that are similar both in terms of content and mode of administration. Second, the data provide extremely large samples, and therefore allow for precise estimates.

While there are some serious limitations with the Census data in regard to the variables available, we do have data on key economic outcome variables like earned income and labor supply, along with race, age, and education, and we have some information on 
location of residence. Even though the variables are quite limited, we are able to establish quite convincingly our central point-that treatment of location is very important in the estimation and interpretation of the decline in black-white disparity in U.S. labor markets over the past six decades.

For our analysis, we restrict attention to men ${ }^{7}$. We begin by dividing respondents on the basis of race-black and non-Hispanic white-and exclude other racial/ethnic groups. We are interested in wages earned by "prime aged" full-time working men, so we restrict attention to men aged 25-55 who worked at least 27 weeks in the previous year ${ }^{8}$. In our analysis we use age, which we have in 31 discrete categories (individual years, 25 though 55 inclusive), education, which we have in 10 categories ("no schooling or kindergarten only" through "more than a bachelor's degree"), and location, which we have for several hundred unique localities ${ }^{9}$.

Our primary focus is on the measurement of black-white wage disparity, conditional on observable characteristics. To give the simplest possible example, suppose we are interested in conditioning only on age. We can proceed as follows. Let $b$ index black individuals and $w$ index white individuals, and let $x_{i}$ be the exact year age of individual $i$. Let $y_{i}$ be the log wage of individual $i$, and let $E\left(y_{b, i} \mid x\right)$ be the expected value of the log wage of that (black) individual given that his age is $x$. Our interest then is in

$$
\Delta=\sum_{x=25}^{55}\left[E\left(y_{b, i} \mid x\right)-E\left(y_{w, i} \mid x\right)\right] f_{b}(x),
$$

where $f_{b}(x)$ is p.d.f. of age among black workers. The idea of looking at the object $\left[E\left(y_{b, i} \mid x\right)-E\left(y_{w, i} \mid x\right)\right]$ is of course that $E\left(y_{w, i} \mid x\right)$ provides a missing counterfactual to the question: What would be the expected log wage of a black worker age $x$ if he were treated in the labor market as a similarly aged white worker? ${ }^{10}$ Then by averaging difference over the age distribution of black workers we are looking at the "average treatment effect on the treated."

Our theoretical reasoning suggests that we need to evaluate $\Delta$ within locations. Since we are interested in the "average treatment effect" over all locations, we can follow an approach comparable to that given in (7) but now let $x$ index a location-age cell (e.g., one cell will be men aged 31 residing in Houston). Notice that in the Census data there will be thousands of such cells, which again we index with $x$. Now we have

$$
\Delta=\sum_{x=0}^{N}\left[E\left(y_{b, i} \mid x\right)-E\left(y_{w, i} \mid x\right)\right] f_{b}(x),
$$

where $N$ is the number of age-location cells.

Finally, there is a tradition in race wage regressions of controlling also for schooling. Given that education in our data is categorized in discrete cells (as discussed in the appendix), we continue to adopt a non-parametric approach. In this instance we simply let $x$ index a location-age-education cell (e.g., high-school educated men aged 31 in Houston), and now let $f_{b}(x)$ represent the distribution of the black population over these cells.

We could directly estimate equation (8) by calculating the conditional means at each point in the distribution of covariates and then taking averages. As a practical matter, we implement an estimation procedure that returns us to the traditional regression 
framework. Let $\hat{\Delta}$ be the non-parametric matching estimator based on the direct approach of (8), and let $\hat{\beta}_{1}$ be the weighted OLS estimator of the regression

$$
y_{i}=\beta_{0}+\beta_{1} R_{i}+\epsilon_{i} .
$$

With a bit of algebra it is possible to establish that $\hat{\Delta} \equiv \hat{\beta}_{1}$ if the weights are constructed as follows:

The first step in constructing the weights is to realize that the Census data themselves come with weights that allow one to mimic the U.S. population. In the appendix we describe our treatment of missing data. Our approach is to assume that data are, conditional on the age-race-education-race cell, missing at random. We thereby construct new weights; for an individual in a particular cell $x^{0}$ the weight, adjusted for missing data, is $w_{1}\left(x^{0}\right)$. Now consider the conditional "probability of being black" for that particular cell:

$$
p\left(x^{0}\right)=\operatorname{Pr}\left(R_{i}=1 \mid x=x^{0}\right) .
$$

Having calculated this probability for each cell, we proceed by defining a new final set of weights, say $w_{2}\left(x^{0}\right)$, as follows:

$$
w_{2}\left(x^{0}\right)= \begin{cases}w_{1}\left(x^{0}\right) & \text { if the worker is black, and } \\ w_{1}\left(x^{0}\right) \frac{p\left(x^{0}\right)}{1-p\left(x^{0}\right)} & \text { if the worker is white. }\end{cases}
$$

Notice that if there is a white worker who is not matched to a black worker at all in the data (i.e., $p\left(x^{0}\right)=0$ ), that individual is dropped from the analysis, and if his characteristics are quite dissimilar from typical black workers in the sample he will be given low weight. Conversely, white individuals who have characteristics that are more typical of the black individuals in the sample are weighted more highly. Intuitively, our re-weighting scheme forces the distribution of covariates in the sample of whites to be identical to the distribution of covariates in the sample of blacks. In the matching context, this is often referred to as "inverse probability weighting"11.

It is important to keep in mind that the estimate of the average treatment effect contains the impact of "unobservables." Thus, for example, if we implement our estimator by matching on all available observables (age, location, and education), we are still leaving out important ways in which black and white workers differ in the labor market. For example, Black et al. (2006) document that black men choose college majors that are systematically less lucrative than those chosen by white men. Because the Census does not contain information on college major (i.e., it is an unobservable), we are unable to condition on this variable. Similarly, Neal (2006) documents large differences in the cognitive test scores of African Americans relative to whites. Lack of such test scores in the Census means that any impacts of that variable are imbedded in the unobservables and their correlation with observable measures.

Finally, we are analyzing wages of men who work 27 weeks a year or more. While the wages of working individuals are indeed important, so are the issues concerning racial differences in labor force nonparticipation. Three well-known facts are germane: First, nonparticipation rates of African American men are higher than the corresponding nonparticipation rates of whites. Second, nonparticipation rates are inversely correlated with education, and presumably nonparticipation also varies with unobservable skills as well. Third, nonparticipation rates have been growing over time ${ }^{12}$. Chandra (2000) gives an excellent review of the issues involved. Here we ignore these concerns, and focus instead 
on the role of location for understanding the racial wage gap among those who are working.

Table 1 gives results. We estimate regression (9) using weighted OLS with weights given in (11). In column (1) we report the outcome in which we match on age only. There is, of course, a compelling reason to match on age, since productivity is related to age, and since age is, from the perspective of labor market participant, exogenous. Having done so, we estimate the black-white log wage gap to be an astonishing -0.74 in 1940 . This gap declines to a still-substantial -0.31 in 1980 and to -0.26 in $2000^{13}$. An important feature of our estimates is convergence; the log wage gap declines by approximately $48 \mathrm{log}$ points over the period of study.

Given the assumptions of our model-that equilibrium always holds and that preferences are homothetic-wage gaps can be thought of as money-metric measures of the welfare disadvantage to being black in the American labor market. These measures are correctly estimated only after matching black and white individuals within labor markets. Column (2) of Table 1 reports the resulting estimates of this latter sort (but not adjusting for educational differences among blacks and whites) ${ }^{14}$. There are substantial differences in the inferences we draw using estimates in column (2), which makes location adjustments, and column (1), which does not. We see, for example, that within local labor markets the $1940 \log$ wage gap is now "only" -0.66 , instead of -0.74 . Apparently in 1940 blacks disproportionately resided in labor markets that had relatively low wages for workers generally. By 2000, though, the racial distribution of residence had changed substantially, and in consequence a log wage gap that accounts for location is larger in absolute value than one that does not, -0.31 vs. -0.26 . Taking this approach we find a convergence of $35 \log$ points, not 48 log points. Put another way, failure to treat location properly leads us to overestimate black-white wage convergence by nearly 40 percent $^{15}$.

Table 1 Black-white gaps in log weekly wage

\begin{tabular}{lccccc}
\hline & $\mathbf{( 1 )}$ & $\mathbf{( 2 )}$ & $\mathbf{( 3 )}$ & $\mathbf{( 4 )}$ & $\mathbf{( 5 )}$ \\
\hline Age & Yes & Yes & Yes & Yes & Yes \\
Education & No & No & Yes & Yes & Yes \\
Location (MSA) & No & Yes & No & Yes & No \\
Location (Region) & No & No & No & No & Yes \\
\hline $\mathbf{1 9 4 0}$ & -0.741 & -0.662 & -0.584 & -0.495 & -0.478 \\
& $(0.0119)$ & $(0.0081)$ & $(0.0093)$ & $(0.0086)$ & $(0.0114)$ \\
$\mathbf{1 9 5 0}$ & -0.511 & -0.485 & -0.400 & -0.365 & -0.348 \\
& $(0.0139)$ & $(0.0108)$ & $(0.0110)$ & $(0.0125)$ & $(0.0126)$ \\
$\mathbf{1 9 6 0}$ & -0.510 & -0.489 & -0.372 & -0.366 & -0.332 \\
& $(0.0070)$ & $(0.0063)$ & $(0.0041)$ & $(0.0050)$ & $(0.0064)$ \\
$\mathbf{1 9 7 0}$ & -0.447 & -0.448 & -0.315 & -0.329 & -0.281 \\
& $(0.0138)$ & $(0.0054)$ & $(0.0057)$ & $(0.0047)$ & $(0.0062)$ \\
$\mathbf{1 9 8 0}$ & -0.308 & -0.332 & -0.238 & -0.256 & -0.218 \\
& $(0.0125)$ & $(0.0031)$ & $(0.0049)$ & $(0.0022)$ & $(0.0042)$ \\
$\mathbf{1 9 9 0}$ & -0.281 & -0.323 & -0.212 & -0.248 & -0.193 \\
& $(0.0054)$ & $(0.0027)$ & $(0.0054)$ & $(0.0022)$ & $(0.0040)$ \\
$\mathbf{2 0 0 0}$ & -0.259 & -0.310 & -0.197 & -0.236 & -0.184 \\
& $(0.0070)$ & $(0.0027)$ & $(0.0049)$ & $(0.0022)$ & $(0.0036)$ \\
\hline
\end{tabular}

Source: Authors' calculations, 1940 to 2000 I-PUMS. Dependent variable is the logarithm of weekly earnings. See the data appendix for details. 
As we have noted, it is common in the literature to condition on both age and education when evaluating wage gaps. The idea is to try to sort out how much of the race "treatment effect" is due to differences in years of formal schooling acquired by workers. We thus conduct our exercise matching on age and education in column (3) and on age, education, and location in column (4). In this case also, inferences about convergence are greatly affected by matching on location: In a specification that does not condition on location, the gap is estimated to decline by 39 log points, but within location the gap declines by $27 \log$ points. Failure to condition on location again leads us to overestimate black-white wage convergence, in this case by approximately 45 percent $^{16}$.

We know of no other empirical work on the black-white wage gap in which analyses take detailed account of location, as we have in columns (2) and (4) of Table 1. However, in the previous literature wage regressions do occasionally include regional indicator variables, so in column (5) we try a specification in which we match on location using Census region indicators only. Such region indicators are not a good substitute for our more detailed location controls. Estimated gaps are consistently lower using this specification than in column (4) - an indication that even within regions, blacks and whites live in systematically different labor markets.

What are the shifting patterns of residence that have such an important impact when we estimate black-white wage gaps? Table 2 provides the basic answer. In that table we report the results of the following exercise: We begin by calculating the extent to which black men disproportionately reside in the South. We do this by constructing an index equal to the ratio of "the fraction of black men aged 25-55 living in the South" to "the fraction of white men aged 25-55 living in the South." This index equals 1 if the same proportion of black men as white men live in the South. We construct a comparable index for urban residency. The table indicates that in 1940 black men were very heavily over-represented in the South-the index is nearly 3 -and substantially under-represented in urban areas. By 2000, the over-representation in Southern residence weakened substantially, and black men were disproportionately likely to live in urban areas.

Clearly, the large changes in residential patterns make an important difference when we are thinking about black-white wage inequality. Over time, blacks have generally moved from low-cost low-wage rural areas, largely in the South, to disproportionately high-cost high-wage urban locations throughout the country. Our empirical work indicates that failure to condition on detailed location causes us to overestimate the absolute

Table 2 Location indices for black men

\begin{tabular}{lcc}
\hline & $(\mathbf{1})$ & (2) \\
\hline Year & Southern residency & Urban residency \\
\hline $\mathbf{1 9 4 0}$ & 2.87 & 0.76 \\
$\mathbf{1 9 5 0}$ & 2.48 & 0.91 \\
$\mathbf{1 9 6 0}$ & 2.19 & - \\
$\mathbf{1 9 7 0}$ & 1.74 & 1.13 \\
$\mathbf{1 9 8 0}$ & 1.69 & 1.18 \\
$\mathbf{1 9 9 0}$ & 1.60 & 1.17 \\
$\mathbf{2 0 0 0}$ & 1.59 & 1.15 \\
\hline
\end{tabular}

Notes: Authors' calculations, 1940 to 2000 PUMS. The southern residency index is the ratio of fraction black men aged 25 to 55 inclusive to white men of the same age. The MSA residency index is, for similar aged men, the ratio of black men to white men residing in an MSA. The 1970 southern residency index is created using the 1 percent state sample rather than the metro sample used in the rest of this paper because region of residency is not uniquely identified for MSAs that straddle the border of the southern region. 
degree of the racial wage disparity in the early years of our analysis (prior to 1970) but to underestimate disparity in each year after 1970 .

More generally, we see the empirical work we present here as underscoring the value of taking into consideration the role of location in the process of evaluating labor market phenomenon. In this respect our work is related to important recent research by Moretti (2013), who shows that careful attention to price differences across locations alters our understanding of changes in inequality in U.S. over the past 30 years.

\section{What if preferences are non-homothetic?}

The structural models we estimate above rely on homotheticity of individual preferences. As it turns out, matters become substantially more complicated if preferences are not homothetic. In particular, the steps we took in deriving equation (6) no longer pertain; equilibrium racial wage disparity varies by location. We examine these issues by looking at two cases-one in which there are location-specific differences in productivity and one in which there is variation in local amenities.

Suppose that minority workers have (unobserved) lower levels of human capital than majority-group workers. Suppose also that there is variation across cities in productivity ${ }^{17}$. The city with higher productivity will have higher wages and in consequence will typically have higher housing prices. In this setting, we are interested in learning how race wage gaps vary across locations.

Continue to let $u^{1}$ and $u^{0}$ be utility levels, respectively, of minority and majority workers. Given that minority workers have a lower level of human capital, and thus within each city lower wages, their utility will also be lower; $u^{1}<u^{0}$. The equality index in a given city with a housing price $p$ is $I=\frac{e\left(p, u^{1}\right)}{e\left(p, u^{0}\right)}$.

We want to know how this index in a low-price, low-productivity city compares to the index in a higher-price city. We conduct this thought experiment by evaluating the derivative of the equality index with respect to the housing price:

$$
\frac{\partial I}{\partial p}=\frac{1}{e\left(p, u^{0}\right)^{2}}\left[e\left(p, u^{0}\right) \frac{\partial e\left(p, u^{1}\right)}{\partial p}-e\left(p, u^{1}\right) \frac{\partial e\left(p, u^{0}\right)}{\partial p}\right] .
$$

With a bit of algebraic manipulation we can rewrite (12):

$$
\frac{\partial I}{\partial p}=\frac{e\left(p, u^{1}\right)}{p e\left(p, u^{0}\right)}\left[\frac{p}{e\left(p, u^{1}\right)} \frac{\partial e\left(p, u^{1}\right)}{\partial p}-\frac{p}{e\left(p, u^{0}\right)} \frac{\partial e\left(p, u^{0}\right)}{\partial p}\right] .
$$

Shephard's lemma indicates that the derivative of the expenditure function with respect to $p$ is the demand for housing. So (13) can in turn can be written in terms of the budget shares of housing for minority workers and majority workers, respectively $s_{H}^{1}$ and $s_{H}^{0}$ :

$$
\frac{\partial I}{\partial p}=\frac{e\left(p, u^{1}\right)\left(s_{H}^{1}-s_{H}^{0}\right)}{p e\left(p, u^{0}\right)} .
$$

This latter expression is positive if minority workers allocate a higher share of their income to housing than do their majority counterparts. Given that minority workers have relatively lower income, this amounts to the assumption that the income elasticity of housing is less than one. As we mention above, there are some estimates that place the permanent income elasticity of housing demand near one, but others do suggest that it is less than one ${ }^{18}$. If so,

$$
\frac{\partial I}{\partial p}>0 \text {. }
$$


Given that cities with relatively high productivity are also cities with higher housing prices in this example, we expect that the wage equality index will be higher in high-productivity cities than in low-productivity cities. This means that for a disadvantaged minority, the equality index will be closer to 1 ; the proportional nominal wage gap will be smaller (in absolute value) in the high-productivity city.

It is quite easy to explain the logic of this proposition. Suppose individuals live in one of two locations-to take a concrete example, say Memphis and Chicago in 1940-and suppose that in each location black workers (the minority in this example) earn less than their white counterparts because of differences in human capital. Suppose further that all workers are more productive in Chicago, owing perhaps to Chicago's industrial agglomerates. In equilibrium we expect Chicago to have higher wages than Memphis and also to have a relatively higher housing price. What about the black-white wage gap in the two cities? Given that the elasticity of demand for housing is less than one, the relatively high housing price in Chicago places a greater burden on the (poorer) black workers than the (richer) white workers. Thus if both black and white workers are indifferent between living in Memphis and Chicago, as they must be in equilibrium, black workers will require a larger "Chicago wage premium" than will white workers; the proportional gap between black and white wages will be smaller (in absolute value) in Chicago than in Memphis. Thus the equality index is higher in the more expensive city (Chicago). This is what (15) shows.

The same conclusion follows if the minority wage gap is instead generated by labor market discrimination rather than human capital differences. Notice, first of all, that under our assumption of costless mobility, a discriminated-against black worker will be willing to live in either city, Memphis and Chicago, only if utility is the same in the two locations. Thus the equilibrium condition (2) continues to hold, as do our subsequent derivations, leading to (15). Again, the resulting wage disparity must be smaller in Chicago than in Memphis. Intuitively, the utility cost must be the same in the two places, and this can happen only if the proportional wage gap is smaller in the location with higher housing prices.

Another mechanism for generating price differentials across locations is differentials in location-specific amenities. In general, the value of a location-specific amenity will vary according to individuals' incomes. For example, good public transportation might be more valuable to individuals who cannot afford a car and good public education is more important to people who don't view private education as a viable option. Similarly, variety in gourmet restaurants is typically more valuable to wealthy individuals. In turn, the value of amenities will be correlated by race if there are race-related differences in income.

As in the example above (with location-specific differences in productivity), the equilibrium black-white wage gap varies across locations. But in this case we can be less certain about the relationship between the black-white wage gap and housing prices.

Our theoretical analysis implies, in short, that there will likely be differences across cities in equilibrium black-white wage gaps if our assumption of homotheticity in preferences is violated. With this in mind, we provide in Table 3 estimated black-white log wage gaps for individual labor markets-for the 14 metropolitan areas with the largest black population concentrations of black men in 1940, 1950, and 1970 through 2000. These estimates match on individuals' age and education (as in column (4) of Table 1) ${ }^{19}$. 
Table 3 Black-white gaps in log weekly wages, by city

\begin{tabular}{lcccccc}
\hline Cities & $\mathbf{1 9 4 0}$ & $\mathbf{1 9 5 0}$ & $\mathbf{1 9 7 0}$ & $\mathbf{1 9 8 0}$ & $\mathbf{1 9 9 0}$ & $\mathbf{2 0 0 0}$ \\
\hline Southern & & & & & & \\
Houston & -0.834 & -0.367 & -0.425 & -0.270 & -0.299 & -0.325 \\
Memphis & -0.742 & -0.454 & -0.461 & -0.319 & -0.343 & -0.248 \\
Atlanta & -0.687 & -0.472 & -0.482 & -0.288 & -0.293 & -0.253 \\
New Orleans & -0.669 & -0.612 & -0.460 & -0.317 & -0.298 & -0.286 \\
\hline South Atlantic & & & & & & \\
Washington & -0.569 & -0.374 & -0.333 & -0.225 & -0.214 & -0.187 \\
Baltimore & -0.444 & -0.333 & -0.341 & -0.254 & -0.280 & -0.266 \\
\hline Northeastern & & & & & & \\
New York & -0.478 & -0.344 & -0.301 & -0.280 & -0.282 & -0.270 \\
Philadelphia & -0.462 & -0.394 & -0.237 & -0.259 & -0.262 & -0.266 \\
\hline Midwestern & & & & & & \\
St. Louis & -0.515 & -0.456 & -0.298 & -0.261 & -0.309 & -0.261 \\
Cleveland & -0.507 & -0.303 & -0.280 & -0.205 & -0.221 & -0.265 \\
Chicago & -0.452 & -0.331 & -0.278 & -0.268 & -0.297 & -0.303 \\
Detroit & -0.376 & -0.237 & -0.208 & -0.188 & -0.206 & -0.244 \\
\hline Western & & & & & & \\
Los Angeles & -0.486 & -0.283 & -0.301 & -0.275 & -0.234 & -0.244 \\
San Francisco & -0.345 & -0.255 & -0.254 & -0.236 & -0.215 & -0.229 \\
\hline F-Statistic & 37.2 & 10.3 & 29.5 & 38.5 & 22.9 & 18.6 \\
\hline Authos cat & & & & & \\
\hline
\end{tabular}

Authors' calculations, 1940 to 2000 I-PUMS. The F-Statistic is for the test of equality of coefficients; in each regression the $p$-value is less than 0.0001 .

The most striking feature of these statistics is the wide variation across cities in estimated log wage gaps. Consider, for example, the estimates from 1940. Southern cities generally had the largest gaps-in the neighborhood of -0.70 to -0.80 -and these gaps are in some cases twice as large (in absolute values) as the gaps observed in cities with the smallest wage gaps. If this variation is an equilibrium phenomenon, it could reflect that productivity in general is higher in cities outside the South.

Of course there are other plausible explanations for this variation. For example, Charles and Guryan (2008) emphasize that there is substantial variation across U.S. locations in prejudice, and that this variation is responsible for some of the variation in black-white gaps in wages. Also, Card and Krueger (1992) document that in the early part of the twentieth century the quality of education afforded African American children was particularly poor in much of the South. Both of these factors are surely at work in shaping the observed patterns.

More generally, there is good reason to think that observed outcomes in 1940 are not an equilibrium outcome in which utility is constant across locations for each racial group. After all, this year was near the beginning of the epochal "second great migration," during which millions of African Americans migrated out of the South, in part, no doubt, to escape poor economic conditions in the South. We are mindful that the assumption of costless migration is often unrealistic in location models, and that this concern might be especially germane for the application at hand. In this case we can still interpret our estimates in Table 1 as a weighted average of wage gaps that vary across different locations. 
Our primary point, in any event, is that if we want to look at black-white wage convergence in the U.S. since 1940 we miss a great deal if we simply look at national averages. Returning to Table 3, which considers cities separately, we notice interesting differences in trends in the black-white wage gap. Perhaps the most striking feature in the table concerns trends in the black-white wage gap post 1970. In the Southern and South Atlantic cities there are substantial reductions in that gap-reductions on the order of 0.10 to 0.20-from 1970 through 2000. In contrast, there was very little narrowing of the blackwhite wage gap after 1970 in other urban locations in the country. Indeed, over that span the gap increased in such populous cities as Philadelphia, Chicago, and Detroit. Observed declines in national black-white gaps in recent decades reflect declines in some locations (especially in the South), along with the relocation of African Americans across cities, rather than black-white convergence that occurred uniformly across the country.

\section{Conclusions}

We have set up a simple model in which prices vary across location. Our model rationalizes a simple approach to estimating racial wage gaps. We show, in particular, that the traditional approach of including a race indicator variable in a Mincer wage regression provides an economically interpretable estimate if one includes location fixed effects in the regression. Of course, most empirical analyses of the black-white wage gap do not include such fixed effects.

Our empirical exercise entails an update of Smith and Welch's classic work on the evolution of black-white wage disparity among men. We find that for the 1940 to 2000 period, we overestimate black-white wage convergence by 45 percent when we fail to condition on location ${ }^{20}$.

More generally, we present concerns about the assumptions that lead to our structural model. In particular, if preferences are not homothetic, it is no longer the case that the racial log wage gap is a constant across locations, even when the racial utility gap is the same across locations (as it must be in equilibrium). Moreover, for many applications, the equilibrium assumption is probably not tenable. A great deal of work remains to resolve these issues as economists seek to better understand the nature of racial inequality in labor markets.

\section{Appendix}

Data appendix for census analysis

All of the Census data for this paper are taken from integrated data sets of the Public Use Micro Samples (IPUMS) that were released in each of these Censuses, 1940 through 2000. See Ruggles et al. (2008) for details.

Respondents were asked about their earnings in the previous year, the number of weeks worked that year, and, at least for the 1980-2000 Censuses, the usual hours worked that year. Baum-Snow and Neal (2009), however, document systematic biases that differ by race and sex in responses to hours worked. We thus investigate results for both weekly earnings and hourly earnings, finding similar results. We report results for weekly earnings.

Our goal is to provide an analysis similar to that of Smith and Welch (1989). Toward that end, we make many data-use decisions that parallel theirs, though there are differences that we outline here. Like Smith and Welch we restrict our analysis to workers who work 
at least 27 weeks. As for age restrictions, Smith and Welch consider men aged 16 to 64 . We are concerned about the growth of enrollment in high school and college, and we do not want to worry about decisions of "early retirement," so we limit our analysis to men 25 to 55 inclusive. To deal with the issue of schooling, Smith and Welch drop men from their sample who are enrolled in school if they work less than 50 weeks a year. Given our age restrictions, we find that adjustment to be unnecessary. Smith and Welch exclude unpaid family workers, military personnel, and the self-employed who are not in the agricultural industry. We also exclude unpaid family workers, military personnel, the self-employed, and all agricultural workers ${ }^{21}$.

We also follow Smith and Welch in limiting the sample to workers whose reported weekly earnings meet a minimum limit on weekly wages and an upper limit. The adopted limits are shown in Table 4.

The limits for 1940 to 1980 are taken from Smith and Welch (p. 522, footnote 5). For 1990 and 2000, we indexed the 1980 values to the CPI and rounded up.

An important concern with the Census data is item nonresponse. Respondents occasionally choose not to answer questions about their age, race, ethnicity, or education level. More frequently, respondents omit answers to questions about hours worked or earnings. Our approach is to drop respondents who do not answer questions about age, race, Hispanic status, education, or earnings. We do, however, increase the weights on other respondents with identical ages, race, and education levels to reflect the missing data by using inverse probability weighting. To be precise, we estimate the probably of a nonresponse, or

$$
\operatorname{Pr}\left(N R=1 \mid X=x^{0}\right)=f\left(x^{0}\right),
$$

where $x$ indexes the age-race-education-location cell, and then we construct weights, $w_{1}$,

$$
w_{1}\left(x^{0}\right) \equiv \frac{w_{0}}{1-f\left(x^{0}\right)},
$$

where $w_{0}$ are the initial Census weights. Thus, if half the people in the age-race-educationlocation cell do not respond to their earnings or hours worked questions, the responders within the cell have their weights doubled ${ }^{22}$. This procedure implicitly assumes that data are, conditional on the age-race-education-location cell, missing at random. Because we condition on age, race, education, and location, this procedure also replicates the Census joint distribution of the age-race-education-location variables.

We face three important issues when it comes to the measurement of education. First, in 1990 the Census Bureau reworked the education question to account for highest degree for those with a college education and some categorical data for lower levels of education.

Table 4 Limits of weekly earnings, by year

\begin{tabular}{lcc}
\hline & Lower limit of weekly earnings & Upper limit of weekly earnings \\
\hline 1940 & 1.50 & 125 \\
1950 & 3.25 & 250 \\
1960 & 6.25 & 625 \\
1970 & 10.00 & 1,250 \\
1980 & 19.80 & 1,875 \\
1990 & 35.00 & 3,000 \\
2000 & 45.00 & 4,000 \\
\hline
\end{tabular}


For instance, in 1990 the Census asked: "How much school has this person COMPLETED? Fill ONE circle for the highest level COMPLETED or degree RECEIVED. If currently enrolled, mark the level of previous grade attended or highest degree received." Response options were: No school completed; Nursery school; Kindergarten; 1st, 2nd, 3 rd, or 4 th grade; 5 th, 6 th, 7 th, or 8 th grade; 9 th grade; 10 th grade; 11 th grade; 12 th grade, no diploma; High school graduate - high school diploma or the equivalent (e.g., GED); Some college but no degree; Associate degree in college - Occupational program; Associate degree in college - Academic program; Bachelor's degree (For example: BA, AB, BS; Master's degree (For example: MA, MS, MEng, MEd, MSW, MBA); Professional school degree (For example: MD, DDS, DVM, LLB, JD); Doctorate degree (For example: PhD, $\mathrm{EdD})$.

Prior to 1990, the Census asked instead about "years of schooling." For instance, in 1980 the Census asked: "What is the highest grade (or year) of regular school this person has ever attended? Fill one circle. If now attending school, mark grade person is in. If high school was finished by equivalency test (GED), mark '12.' Response options for highest grade attended were: Never attended school; Nursery school; Kindergarten, and these further options: Elementary through high school (grade or year: 1, 2, 3, 4, 5, 6, 7, 8, 9, 10, 11, 12); College (academic years: 1, 2, 3, 4, 5, 6, 7, 8 or more).

Drawing consistent inferences with schooling data drawn these two ways is in principle quite simple if the two types of questions have a similar structure of measurement error. Unfortunately, for the 1990 Census, Black et al. (2003) document that the education questions exhibit significant measurement error and that the degree of measurement error is correlated with race. Moreover, there was a dramatic increase in the educational attainment of Americans over the period. For instance, in 194088 percent of blacks and 64 percent of whites between the ages of 25 and 60 did not have a high school education, and only 2 percent of blacks and 8 percent of whites had a bachelor's degree or better. By 2000, only 9 percent of blacks and 5 percent of whites did not have a high school degree while fully 33 percent of whites and over 19 percent of blacks had a bachelor's degree or better.

In our regression analysis we treat education in a non-parametric way, and given the available data, we use the following ten education categories: no formal education or kindergarten only, 1 to 4 years, 5 to 8 years, 9 years, 10 years, 11 years, 12 years, some college but no bachelor's degree, bachelor's degree, and more than a bachelor's degree.

Finally, there is the issue of the measurement of location. Because of the growth in cities and changes in disclosure policy, the identification of metropolitan statistical areas (MSAs) varies over time. In 1960 (the first public use micro sample that the Census Bureau released), the only geography identified was State of residence. As a result, we cannot conduct the same location analysis of interest to us with the 1960 data; we use only an urban indicator interacted with an indicator for state of residence. In 1940, 1950, and 1970 through 2000, we use MSA of residence for those respondents living in a MSA. For those respondents not living in an identified MSA, we use an indicator for state of residence. Hence, we exploit the geographical variation that is generally available to us. There are, however, a few additional noteworthy limitations:

First, residents of some current MSA's are not separately identified in the early censuses, but are so identified subsequently. For example, in the 1940, Orlando residents are treated as individuals living in "rural" Florida, but in later years are broken out as part of an Orlando MSA. Similarly, Las Vegas is identified only starting in 1970. There are a host 
of smaller towns that are only identified in later years. Moreover, MSAs can be created from regions that were previously a part of different MSAs. This is a particular problem in the densely populated areas of the east and west coasts. Finally, for areas that are only identified as "rural" we may be mixing residents from very different areas of a given state. For example, this designation mixes residents of the desert areas of Southern California with residents of rural Northern California, who may face very different labor markets and price levels.

For the 1940 through 1970 Censuses, we use a one-percent sample of respondents, and from 1980 to 2000, we use the five-percent sample, which, along with population growth, provides much larger sample sizes and much more precise estimates ${ }^{23}$. Finally, we note an important data limitation with the 1950 Census. In 1950, only the "sample line" respondents were asked about education and earnings by the Census Bureau. Hence, only about 3.3 percent of the population was given these questions. Thus, estimates from the 1950 Census are considerably less precise than estimates from even the 1940 Census.

In 1960 and 1970, the Census asked only for hours of work and weeks of work on intervals. To impute the actual levels, we took information from the 1980 Census and calculated the average weeks (or average hours) conditional on the being in the relevant category. The exact imputed values are presented in Table 5.

Prior to 1980, the Census did not ask the usual hours worked so we used hours last week as a proxy. In 1980, conditional on both reports being positive, the correlation is only 0.61 . While quite low, this correlation is not materially different than those found in validation studies; see Barron et al. (1997) for a discussion.

\section{Endnotes}

${ }^{1}$ See Mincer (1974).

${ }^{2}$ Charles and Guryan (2008) document patterns of black-white wage disparity consistent with Becker's model of taste-based discrimination. Many important papers speak to the emergence of black-white differences in human capital development. For example, Cunha et al. (2006) provide an insightful analysis of human capital development, including the emergence of racial and ethnic disparities, and provide an extensive reference to the literature; Card and Krueger (1992) analyze the consequences of school quality for black-white earnings differences; and Neal and Johnson (1996) and Neal (2006) demonstrate the importance of cognitive ability (measured when individuals are young) for subsequent labor market success.

${ }^{3}$ Through out the paper, we will refer to locally priced goods and services as "housing," which surely has the largest budget share among locally priced goods. Of course, many

Table 5 Imputed values of weeks and hours of work

\begin{tabular}{lccc}
\hline Interval & Imputed weeks & \multicolumn{1}{c}{ Interval } & Imputed hours \\
\hline $1-13$ weeks & 1.1 & $1-14$ hours & 8.57 \\
$14-26$ weeks & 21.4 & $15-29$ hours & 21.95 \\
$27-39$ weeks & 33.3 & $30-34$ hours & 30.64 \\
$40-47$ weeks & 43.4 & $35-39$ hours & 36.35 \\
$48-49$ weeks & 48.3 & 40 hours & 40 \\
$50-52$ weeks & 51.8 & $41-48$ hours & 45.46 \\
& & $49-59$ hours & 51.41 \\
\hline
\end{tabular}


goods and services are locally priced (e.g., haircuts are more expensive in Chicago than in Peoria). The cost of living varies widely between cities. Compare, for example, December 2009 cost of living index from city-data.com for Austin (87.2) and Los Angeles (166.6).

${ }^{4}$ There is an important caveat to the Mincer theory: Black et al (2009) show that $\beta_{2}$, the "return to education," will differ by location if preferences are not homothetic. Here, though, we are assuming homotheticity, and in that case returns are the same for each location.

${ }^{5}$ Location fixed effects can be safely omitted only if the vector of location indicator variables is orthogonal to other included variables, in which case those effects are absorbed into the error term. As we show below, though, black and white workers differ substantially in location patterns.

${ }^{6}$ The is is a central point in the literature on price indices. See, for example, Samuelson and Swamy (1974). In our context homotheticity means that the income elasticity of housing is 1. This might not be too far off the mark. In Epple and Seig's (1999) general equilibrium model, the permanent income elasticity of housing is estimated to be 0.94 . Drawing on evidence from partial equilibrium empirical analysis, Harmon (1988) places it at 1, while Haurin and Lee (1989) give an estimate of 1.1.

${ }^{7}$ Female labor markets are equally interesting, and we intend to evaluate black-white wage gaps among women in future work.

${ }^{8}$ We exclude unpaid family workers, military personnel, the self-employed, and those employed in agriculture. See the data appendix for more detail. In general we pattern our exclusion rules after Smith and Welch (1989), although there are some substantial differences. The data appendix also outlines how we construct the key wage variable.

${ }^{9}$ The data appendix discusses our location variables. These vary somewhat over the 60 years of analysis.

${ }^{10}$ Notice that the "treatment" here is not merely the absence of potential racial discrimination in the labor market. Being treated as a white person includes other facets, including improved pre-market conditions that affect human capital.

${ }^{11}$ See Hirano et al. (2003) and DiNardo et al. (1996) for discussions. See Black et al. (2006; 2008) for applications to discrete data.

${ }^{12}$ Furthermore, much evidence (e.g., Black et al. 2002, and Autor and Duggan 2003) suggests this nonparticipation due to disability is quite sensitive to prevailing economic opportunities, particularly for the low skilled. In addition, the increased incarceration of black males, noted by Western (2006) and others, also makes the use of observed wages problematic.

${ }^{13}$ For small values the log wage gap is approximately equal to the percentage wage gap. This approximation is not very good, though, for gaps as large as those we observe here. The percentage wage gaps implied by our estimates for 1940 through 2000 are, respectively, $-0.52,-0.40,-0.40,-0.36,-0.27,-0.24$, and -0.23 . By way of comparison, Smith and Welch (1989) give estimates for 1940 through 1980, respectively: $-0.57,-0.45$, $-0.42,-0.36$, and -0.27 . The basic story is of course the same in the two accounts; differences presumably have to do with differences in our handling of certain data issues, as outlined in the appendix.

${ }^{14}$ In each column, the standard errors are clustered on the level of the "cells" in our nonparametric analysis. We also checked the impact of clustering at the MSA level. While 
the standard errors were larger (typically about two to three times as large), the increase appears to be the result of the reduction in the degrees of freedom rather than correlation within the MSA. Thus, we kept our standard errors clustered at the level in which our data vary.

${ }^{15}$ One might be concerned about selection across locations. Our goal in this paper is to show that ignoring locational differences, as other studies have done, leads to inaccurate estimates. In our estimation, therefore, we treat the selection across locations as exogenous.

${ }^{16}$ Estimates reported in Table 1 use as the dependent variable, log weekly wage, the same variable examined by Smith and Welch. It turns out that there are differences between black and white workers in the number of hours typically worked per week, so we might alternatively evaluate hourly wages in constructing racial wage gaps. Results of this latter analysis, however, are very similar to those one would draw from Table 1 . We substantially overestimate black-white wage convergence over the 1940-2000 period if we fail to account for shifting patterns of location. ${ }^{17}$ While there has been much work on possible causes of such productivity differences (e.g., see Acemoglu 1996; Glaeser and Mare 2001, and other work on agglomeration), we are agnostic here about the source of this variation.

${ }^{18}$ See, for example, Rosen (1985).

${ }^{19}$ As discussed in the appendix, we lack the necessary data to conduct this exercise for 1960 , and so omit that year from our analysis.

${ }^{20}$ As we note above, pessimistic as our results are, they may still understate the current levels of labor market disparity, as we do not account for racial differences in participation or unemployment. See, e.g., Black (1995), Chandra (2000), Neal (2006), and Ritter and Taylor (2011).

${ }^{21}$ Because of the increased mechanization of agricultural production in the U.S., there has been a dramatic reduction in farm labor and a corresponding increase in the size of farms; farming has become quite capital intensive. It is therefore difficult to separate the returns to capital from the returns to labor. We exclude wage-and-salary agricultural workers because payments to workers often involve payments in-kind, which makes the valuation of the wage paid difficult. Of course, the exclusion of agricultural workers has little effect in 2000, but represents a major exclusion for the early years. Excluding self-employed agricultural workers has the added advantage of rendering the 1940 Census compatible with subsequent Decennial Censuses, as the Census did not ask for farm earnings in 1940.

${ }^{22}$ See, e.g., Wooldridge (2007) for a discussion.

${ }^{23}$ Prior to 1980, the Census did not release the five-percent samples.

Competing interests

The IZA Journal of Labor Economics is committed to the IZA Guiding Principles of Research Integrity. The authors declare that they observed these principles.

Acknowledgements

We gratefully acknowledge support from Eunice Kennedy Shriver National Institute of Child Health and Human Development (RO1 HD062747). The content is solely the responsibility of the authors and does not necessarily represent the official views of the Eunice Kennedy Shriver National Institute of Child Health and Human Development or the National Institutes of Health. Helpful comments on earlier drafts were provided by David Card, Enrico Moretti, and seminar participants at UC Berkeley, University of Chicago, Duke University, IUPUI, University of Missouri, University of Michigan, Purdue University, University of Texas, University of Wisconsin-Madison (IRP), Washington University in 
St. Louis, University of Mississippi, Lincoln Institute of Land Policy, Federal Reserve System Committee on Applied Micro Conference 2010, SOLE 2011, NASMES 2011, RES 2011, WEAI 2009, and NARSC 2009.

Responsible editor: Pierre Cahuc

\section{Author details}

${ }^{1}$ University of Chicago, NORC, and IZA, Chicago, USA. ${ }^{2}$ University of Mississippi, University, USA. ${ }^{3}$ Duke University,

Durham, USA. ${ }^{4}$ Carnegie Mellon University, NORC, and IZA, Pittsburgh, USA.

Received: 7 March 2013 Accepted: 22 April 2013

Published: 1 May 2013

References

Acemoglu D (1996) A Microfoundation for social increasing returns in human capital accumulation. Q J Econ 111(3): $779-804$

Autor D, Duggan M (2003) The rise in the disability rolls and the decline in Unemployment. Q J Econ 118(1): 157-205

Barron J, Berger M, Black D (1997) How well do we measure training J Labor Econ 15(3): 507-528

Baum-Snow N, Neal D (2009) Mismeasurement of usual hours worked in the census and ACS. Econ Lett 102(1): 39-41

Black DA (1995) Discrimination in an equilibrium search model. J Labor Econ 13(2): 309-34

Black D, Daniel K, Sanders S (2002) The impact of economic conditions on participation in disability programs: evidence from the coal boom and bust. Am Econ Rev 92(1): 27-50

Black, D, Haviland A, Sanders S, Taylor L (2006) Why do minority men earn less? A study of wage differentials among the highly educated. Rev Econ Stat 88(2): 300-313

Black D, Haviland A, Sanders S, Taylor L (2008) Gender wage disparities among the highly educated. J Human Resour 43(3): 630-659

Black D, Kolesnikova N, Taylor L (2009) Earnings functions when wages and prices vary by location. J Labor Econ 27(1): 21-47

Black D, Sanders S, Taylor L (2003) Measurement of higher education in the census and CPS. J Am Stat Assoc 98(463): 545-554

Card D, Krueger A (1992) School quality and black-white relative earnings: a direct assessment. Q J Econ 107(1): 151-200

Chandra A (2000) Labor market dropouts and the racial wage gap: 1940-1990. Unpublished dissertation, University of Kentucky

Charles K, Guryan J (2008) Prejudice and wages: an empirical assessment of Becker's The Economics of Discrimination. J Pol Econ 116(5): 773-809

Cunha F, Heckman JJ, Lochner L, Masterov DV (2006) Interpreting the evidence on life cycle skill formation. In: Hanushek EA Welch F (eds). Handbook of the Economics of Education, Volume 1, 697-812

DiNardo J, Fortin N, Lemieux T (1996) Labor market institutions and the distribution of wages, 1973-1992: A semiparametric approach. Econometrica 64(5): 1001-1044

Epple D, Sieg H (1999) Estimating equilibrium models of local jurisdictions. J Pol Econ 107(4): 645-681

Glaeser EL, Mare DC (2001) Cities and skills. J Labor Econ 19(2): 316-342

Harmon O (1988) The income elasticities of demand for single-family owner-occupied housing: an empirical reconciliation. J Urban Econ 24(2): 173-185

Haurin DR (1980) The regional distribution of population, migration, and climate. Q J Econ 95(2): 293-808

Haurin DR, Lee K (1989) A structural model of the demand for owner-occupied housing. J Urban Econ 26(3): 348-360

Heckman JJ, Lochner LJ, Todd PE (2006) Earnings functions, rates of return and treatment effects: the mincer equation and beyond. In: Handbook of the Economics of Education, volume 1, 307-458

Hirano K, Imbens G, Ridder G (2003) Efficient estimation of average treatment effects using the estimated propensity score. Econometrica 71(4): 1161-1189

Mincer J (1974) Schooling, Experience, and Earning. National Bureau of Economic Research, New York

Moretti E (2013) Real wage inequality. Am Econ J: Appl Econ 5(1): 65-103

Neal D (2006) Why has black-white skill convergence stopped? In: Hanushek E Welch F (eds). Handbook of the Economics of Education, Volume 1, Chapter 9, 511-576. Elsevier Science, Amsterdam

Neal DA, Johnson WR (1996) The role of premarket factors in black-white differences. J Pol Econ 104(5): 869-895

Ritter JA, Taylor LJ (2011) Racial disparity in unemployment. Rev Econ Stat 93(1): 30-42

Roback J (1982) Wages, rents, and the quality of life. J Pol Econ 90(6): 1257-1278

Rosen HS (1985) Housing subsidies: effects on housing decisions, efficiency, and equity. In: Auerbach AJ Feldstein M (eds). Handbook of Public Economics, Vol. 1, 375-420, North Holland, Amsterdam

Ruggles S, Sobek M, Alexander T, Fitch C, Goeken R, Kelly P, King M, Ronnander C (2008). Integrated Public Use Microdata Series: Version 4.0. Technical Report

Samuelson PA, Swamy S (1974) Economic index numbers and cannonical duality: survey and syntheis. Am Econ Rev 64(4): 519-564

Smith JP, Welch F (1989) Black economic progress after myrdal. J Econ Lit 27(2): 519-564

Western B (2006) Punishment and Inequality in America. Russell Sage Foundation, New York

Wooldridge J (2007) Inverse probability weighted estimation for general missing data problems. J Econometrics 141(2): 1281-1301

doi:10.1186/2193-8997-2-2

Cite this article as: Black et al:: The role of location in evaluating racial wage disparity. IZA Journal of Labor Economics 2013 2:2. 